\title{
Graduate Evaluations of the University Armed Service Units Experience
}

\begin{abstract}
Annually, around 2,000 students with experience of the OTC, UAS or URNU leave university and enter paid employment. We can assume, if we extrapolate from the evidence presented in Chapter 3, that having maintained a relationship with their unit for a significant period of time during their studies, these individuals recognised at the time a value to their USU participation. The question which then follows is whether, and in what ways, that experience is understood as having value after graduation. In this chapter, we explore four quite distinct ways in which graduates perceive there to have been value in their USU experience. We consider what they say about value, specifically in the workplace and around their employability, we assess the idea that USU graduates might be 'defence-minded' for life and how that might be understood and seen as manifest by graduates, we consider how individuals assessed their own value to the USUs and the armed forces, and we explore the wide-ranging perceptions of the graduates about the value of the USUs.
\end{abstract}

\subsection{The sample of graduates}

Chapter 2 outlined the methodology used for this part of the study, which involved semi-structured interviews with individuals across a range of ages and experiences of USUs. The schedule of interview questions is given in Appendix 2. All direct quotations included in this chapter are taken from transcripts of those interviews.

How to cite this book chapter:

Woodward, R, Jenkings, K N and Williams, A J. 2015. The Value of the University Armed Service Units. Pp. 101-138. London: Ubiquity Press. DOI: http://dx.doi. org/10.5334/baq.d. License: CC-BY 4.0. 


\subsubsection{Demographic features of the sample}

We interviewed 54 individuals ( 38 men and 16 women). The gender ratio roughly matched that of the current student cohort, but did not necessarily reflect that in place at the time when interviewees were members of their USU. Indeed, two women talked of their novelty as women in units that had previously been closed to women, or had not had women participants until they themselves had joined.

We did not ask interviewees for their age directly, because it was the period of their past participation which was more significant. We did however, establish from interviewees' narratives sufficient information to allocate each individual, very crudely, to an age cohort, as follows:

- Two interviewees (3\% of the sample) started university between 1953 and 1962, and were assumed to be in their 70s at the point of interview.

- Three interviewees (5\% of the sample) started university between 1963 and 1972 , and were assumed to be in their 60 s at the point of interview.

- Four interviewees (7\% of the sample) started university between 1973 and 1982 , and were assumed to be in their 50 s at the point of interview.

- Five interviewees (10\% of the sample) started university between 1983 and 1992, and were assumed to be in their 40s at the point of interview.

- 22 interviewees (40\% of the sample) started university between 1993 and 2002 , and were assumed to be in their 30s at the point of interview.

- 18 interviewees (33\% of the sample) started university between 2003 and 2012 , and were assumed to be in their 20 s at the point of interview.

Three quarters of the sample were therefore discussing a USU experience in the previous 20 years, and the remainder had an experience further back in time. This was useful in order to generate data (from more recent graduates) which spoke to contemporary issues and concerns, whilst providing data (from older graduates) through which we could assess continuity and change. By interviewing graduates across a range of age cohorts, we were able to put together a picture of the changing ways in which the USU experience might (or might not) impact in different ways at different points in working lives.

Our graduate interviewees were a highly educated group. In terms of undergraduate or first degrees, 3 had medical or dental degrees, 18 had degrees in science subjects, 17 had degrees in social science subjects (of which 7 had law degrees and 7 had geography degrees), 10 had degrees in arts and humanities subjects and 6 had degrees in vocational applied sciences or applied social sciences. In addition, around 15 had a postgraduate qualification of some kind, either academic (Masters or $\mathrm{PhD}$ qualification) or a professional qualification for competency to practice (for example, in law or accountancy). 


\subsubsection{University and university armed service units experience}

The universities represented by our interviewees ranged across the higher education sector, and included established institutions including the ancient universities, the red brick universities established for the purposes of civic education in the $19^{\text {th }}$ century, the plate glass institutions reflecting the impact of the Robbins reforms of the 1960s, and the new universities, former polytechnics and technical training institutions granted university status and degree-awarding powers from 1992 onwards. Interviewees were not sampled according to the type of university they attended, but we are pleased that the final sample reflected institutions across the diversity of the establishments and mission groups in the sector.

The vast majority of interviewees were USU participants whilst taking their undergraduate degree, with some continuing whilst undertaking postgraduate study. Four interviewees had non-standard participation patterns: two had had a year abroad as part of their degree programme (and discussed their efforts to maintain unit participation whilst away), one Commonwealth student had participated for a single year as a visiting student to a UK university whilst on his degree programme and one individual had participated as a student whilst at sixth form college rather than at a university.

The broad aim with the sample was for a proportional balance across the three service units. Allocating an individual to a service unit was complicated by the fact that some individuals had participated in more than one unit (for example, a period of time in the OTC, followed by participation in an URNU). The final sample comprised 24 former OTC participants, 13 UAS participants and 17 URNU participants, when allocated according to the first unit each individual joined. There was, therefore, a slight bias in the sample towards URNU, which is the smallest of the three USUs. Overall, the aim was to capture the views and experiences of former members from across the three services rather than compare experiences between services. We were reliant on individuals coming forward for interview, and did not set out to interview individuals with experience in a particular geographical area. In terms of geographical spread, there was a slight bias in the sample towards graduates from USUs in Eastern Scotland (Dundee, Stirling), Newcastle, Manchester, Liverpool, the East Midlands, Oxford, Cambridge and London. We did not interview anyone with USU experience from the South West (except for one from the University of the West of England) or Wales. The effects of this on the research findings are negligible as it is unlikely (given that units are centrally directed) that individual units have processes, structures or practices which are hugely at variance with each other, and the continuous rotation of COs and training staff through units produces a commonality of experience across units. Although some individuals identified some units as having specific strengths, this was interpreted as a reflection of the loyalty and affection which units generate amongst their former members, even years after graduation. 


\subsubsection{Patterns of employment}

All the graduates interviewed were either in professional employment (including individuals on maternity and parental leave), ran their own business or had retired from professional employment, with the exception of one interviewee who was starting his first job shortly after the interview, having very recently graduated. We use the terms 'professional' and 'graduate' employment interchangeably in this book, to indicate employment which requires, at least at entry point, education to tertiary level, whilst noting the difficulties of defining these terms (something which professional careers advisors recognise). ${ }^{61}$

The majority of our interviewees worked (or had worked) in the private sector (for example, business services, the legal profession, the financial sector, engineering, aviation, media and logistics) and a much smaller proportion in public sector employment (for example, the National Health Service, the civil service, policing and higher education). Sampling was not structured by sector of employment or by employment status; it is therefore merely an effect of the sampling strategy outlined above that the majority were working in professional occupations in the private sector. The career pathways of our interviewees were completely diverse, and defy any attempt at categorisation; there is diversity in the sample in terms of use of degree, strategies for determining career pathways, availability of opportunities and influence of lifestyle factors in careers. What is evident through comparisons between individual interviews across the dataset are the effects on graduate employment of shifts across the decades in terms of labour market elasticity and structure, with the demise of full employment, the rise of a tighter and more competitive graduate labour market in the 1980s and again in the post-2008 financial crisis period, the emergence of portfolio careers, of self-employment and of a small business economy around consumer, health and producer services. We can also identify the expansion and consolidation of employment rights for parents, particularly women taking maternity leave, and the expansion of employment opportunities for women into sectors where they had had a minimal presence in previous decades.

\subsubsection{University armed service units awareness}

Given the age range of our interviewees and thus the effect of generational change, and given the range of universities which they attended and thus the very different sets of circumstances potentially shaping decisions to join a USU,

${ }^{61}$ Office for National Statistics. (2013). Graduates in the UK Labour Market. London: Office for National Statistics. Further details are available from the Association of Graduate Careers Advisory Services: http://www.agcas.org.uk/articles/746--non-graduate\%20jobs-data-anAGCAS-perspective 
it is virtually impossible to be definitive on patterns of pre-university awareness about USUs amongst our sample. Broadly, our respondents appeared to mirror the experiences of current students (see 3.3. above, on joining a USU), with a proportion finding out through Freshers' Fairs ('walking around the Freshers' Fair with some friends and the guy quite literally grabbed me and [...] said "we have a ship if you want to join us"), some joining following advice from armed forces careers advisors, or following experience in the cadets (when asked directly, just under half said that they had been in the cadets at school), or advised by friends or family who had been members. Given that people were being asked to recall something that might at the time have seemed very incidental, and which may have happened long ago, it is hard to be definitive on this point, but it would suggest that both Freshers' Fairs and cadets' experiences are significant. Over half had no family connection with the armed forces beyond grandparents.

\subsubsection{Participation in the Reserves}

We intentionally sampled for interview those who had not pursued a full-time career (of any duration) with the UK armed forces. This is because one of our key research questions concerned the value of the USU experience in the civilian workplace. We made this explicit in our call for research participants. We did not, however, explicitly exclude those who had served as reservists. A number of interviewees came forward who had previous or current experience with the Reserves (across the three armed forces). We decided to include them in the sample for two reasons. First, we were interested in the transferability of skills from military training to civilian employment contexts, and recognised that this process is not unique to the USUs but features as a factor for those working as, and employing, reservists. Second, whilst the interviews were being planned and then conducted, the Government announced the first of a series of interventions under the Future Forces 2020 programme, designed to reduce the number of full-time Regular members of the armed forces and increase the proportion of reservists, particularly in the British Army.

A total of 22 respondents had had, or maintained at the time of the interview, a relationship with the Reserves following their USU experience, and six of the sample had had a relationship of some kind with the Reserves whilst a student. Where this was the case, some additional questions were asked about this experience. We have identified an effect of this in our sample; it could be argued that the sample included over-representation from those who had had additional socialisation into the armed forces further to their USU experience. It would, however, be virtually impossible to quantify the extent to which the sample was skewed because of this (bearing in mind, for example, that some interviewees were discussing Reserves participation 
up to 40 years previously, under an armed forces structure and organisation which was very different to the present). However, despite the possibility of over-representation amongst those with greater armed forces experience, in our view this was balanced by the additional insights which these individuals were able to bring to the research. In being able to compare and contrast their USU and Reserves experiences, we were able to tease out during interview something of the specificity of each and commonality of both. Furthermore, given that at the time of writing the expansion of the Reserves remains a pressing policy issue, and given that much of our analysis suggests findings which might usefully inform ongoing debates about mechanisms for the expansion of the Reserves and the role of the USUs in that, we consider the possible over-sampling of reservists to be a strength rather than a weakness of the data. Indeed, a few interviewees who had not been in the Reserves were considering the possibility of joining as their living and working patterns opened up the opportunity to do so.

\subsection{The value of university armed service units experience in the workplace}

In this section, we assess the value or otherwise of the USU experience in the workplace. Note that the research was exploring the question of value beyond that outlined by the USUs. The focus on workplace achievement is not explicitly stated as part of the USU's missions, which are more broadly framed (see Chapter 1). As we have seen in Chapter 3, contemporary student USU participants see the experience as potentially extremely valuable in applying for and performing a graduate-level job, and this idea has to have foundation in something concrete for it to have the tenacity that it does. We were interested, then, in whether it is indeed the case that the USU experience has a value in the workplace, and one way to evaluate this was to talk to graduates themselves, who were working and who had been through a recruitment process (often many times over the course of a career).

We speculated that there were two primary ways in which the value of the USU experience to the workplace was manifest. It could be evident as individual, personal benefits which graduates with USU experience identify as accruing to them on that basis, which could then have value in the workplace, either directly or indirectly through transferable skills. It could also be evident in benefits for employers in the execution of employment tasks, which could be enhanced through the skills and training which individuals receive through the USU (for example, through knowledge of defence-related practices or terminologies). We were also interested in how value in the workplace might vary with time across an individual's engagement with the labour market from the point of application onwards. In this section we consider the utility in the job application process, and in the performance of a graduate job. 


\subsubsection{Applying for a job}

We were interested in exploring with graduates the use or otherwise that they made of their USU experience when applying for a job (note that we were focused on the application process, rather than on the decision to pursue a job in a particular sector on the basis of the USU experience). This seemed significant because of the emphasis current students placed on the utility of the USU experience to the job application process (see section 3.7 above).

The interviews explored how the graduate's USU experience was framed within an application. Graduates mentioned their pride in their association with the units, and also the profile and kudos associated with the British armed forces as a brand. But more specifically, particularly for more recent graduates, 'it gives you demonstrable qualities' which make an application or CV stand out. The USU experience can be used prominently to complement or act in lieu of work experience (that is, civilian paid employment):

'My CV maybe has less work experience on it, but because of that I actually have a greater focus on my OTC experience [...] the second thing on my CV [...] is actually NUOTC.

Interviewees, particularly more recent graduates, appeared to view their USU experience primarily as a demonstration of aptitude for work, rather than as part of their education. The experience was thought to show an individual as having been motivated to something requiring commitment, and to have managed to do this successfully whilst also studying for a university degree. Having USU experience on a CV was believed to make an application stand out, even if the recruiter knew little about what participation involved.

The USU experience was particularly prominent for those applying for their first jobs. A recent graduate working in the media industry said:

'[...] my time in the University Air Squadron was the main emphasis of every single job application [...] when I was applying for this internship $[\ldots]$ that I am on at the moment, the very fact that I was in the university air squadron, and I've been told this from my boss while I have been here, did stand me out from the applications [...] in interviews, every single question they had I could relate it back to being in an air squadron.'

The experience provides examples about which to speak. There may be differences of emphasis because CVs and applications are tailored to specific jobs:

'[...] the ones which I focused my university air squadron elements on and really emphasised, were the ones that had a direct military connection.' 
'When I was going for different roles within marketing I made more emphasis on my English degree, my writing and my analytical skills, and when I was going for more managerial things I [emphasised at university] captaining certain sports and the managerial stuff with the URNU.'

Other graduates discussed how elements of a USU experience would be drawn on to fit an application; one discussed emphasising 'all this crazy stuff like flying and climbing and all that adventure training stuff' for job applications in broadcast journalism, and the more managerial and organisational skills were emphasised in applications for more desk-based jobs.

We were interested in what, exactly, the USU experience was used to demonstrate, where it was used on an application. Graduates talked primarily about transferable skills:

'The skills you do pick up [...] skills that industry itself will find useful [...] leadership skills, organisation skills, time management skills [...] it gives you demonstrable qualities that when an employer picks up a list of CVs from graduates, those that actually have degrees and experience that are relevant - [it] makes them stand out.'

This idea of having an edge, standing out, being somehow distinctive, is central to the narratives of younger graduates, reflecting the competitive graduate recruitment market, and applicant strategies presumably suggested by careers advisers (and indeed university educators and USU staff) to focus on the transferability of skills. But some skills have particular purchase when understood as originating in a military context. Evidence of leadership ability was frequently cited, along with the use of the USU experience to demonstrate time management (meeting demanding educational and military training commitments), resource allocation and use, and motivation. Reference to generic transferable skills developed in the USU figured in graduates' recollections of their applications. However, there was little sense that graduates thought that their USU experience somehow spoke for itself. The key lay in being able to articulate how and why a particular skill or experience in a USU context might apply in the workplace:

'It might seem strange to try and sell yourself in the book publishing world by using my experience in the military but I actually did that. I knew I was willing to work hard at all hours for not a huge amount of money, I knew I could work as a team [...] I was trying to get into quite a creative role, which is very difficult to get into.'

Graduates also discussed how they might refer specifically to the USU's military context and thus to military-specific knowledge in emphasising their skills. Distinct in the group of graduates were those with UAS experience who had then proceeded to careers related to aviation, and those with URNU experience 
who were able to draw on sea-faring experience for maritime roles (including an applicant drawing on URNU experience for a job with a shipping law firm, 'I had basic knowledge of ship handling, which was more than most trainee lawyers had'). Again, the knack in using this in job applications was to demonstrate the applicability of military-context skills to a civilian workplace, rather than just assume it:

'I talked a lot about leadership in the Royal Navy, in the Royal Navy Unit and on the ship, in deployments'.

One mentioned his ability to understand hierarchies and command structures and to then communicate that as a skill, because:

' $[. .$.$] when you've had that military training, you think: "right, the big-$ ger picture - how does my role here actually affect my bosses job, or the person under me?"”

Another talked about how he deliberately drew parallels between his responsibilities in an URNU and analogous civilian business tasks:

'[I was] kit officer, I had to buy, design and sell merchandise for the unit, which was a self-defined role, I could do as little or as much as I wanted, but it basically amounted to running a small business for a year, which I thought looked very good on my CV. PR and recruitment: I helped with recruiting new students in my final year $[\ldots]^{\prime}$

Placing emphasis in a job application was not, however, a universal activity. Four issues emerged here in the graduate interviews. The first was a caution in overplaying this one experience:

'I certainly don't remember it being at the top of my list.'

'I don't want to overplay it, partly because you want to show you've got breadth.'

'I'd try not to just use URNU experience because it would be too limited.'

'I didn't list them as a job - however, I did list them in my interests - I felt that having those on there would make my application stand out.'

The second concerned time: as might be expected, the significance of USU participation and related activities on a CV diminishes as applicants progress through their careers accumulating more specific experience of greater relevance to a job application at that particular career stage. 'I had lots of other things to talk about', noted one. 'It's one line - whereas it used to be three paragraphs' reflected another. There was a marked difference between older graduates ('I don't think it even gets a mention on my CV now - but you're 
talking 15 years ago') and more recent graduates ('for each of the examples we had to give [in the application], a lot of experience [...] came from the URNU').

The third issue shaping the use of USU experience in job applications was graduate perceptions of the likely reception by a potential employer to the idea of a USU itself, and USU experience. This was explained in a number of ways; one graduate working in Northern Ireland had left it off his CV for personal security reasons, not wanting direct visible association with the British Army. The palatability of military association was identified in other contexts:

'It wasn't trendy when I came out of university to say very much that would be considered right wing - I shut up about it a bit - it was a oneliner $[\ldots]$ '

'I dropped it after an unpleasant interview experience.'

Another (more recent) graduate chose deliberately to portray her UAS involvement as an additional interest rather than work experience when applying for jobs in a sector which she felt was antipathetic to the idea of military activities and institutions:

'[...] the [jobs] which maybe had an environmental focus or shied away from defence or military, I didn't emphasise what I had done. I used it more as a - this was one of my hobbies [...] Different amounts of emphasis depending on the connection that the organisations had to the military.'

An older graduate with UAS flying experience, and who listed this and shooting as hobbies on her CV felt that she had been chastised for these activities in several interviews (perhaps a reflection of that time period). Clearly, graduates had to consider a recruiter's receptivity to the idea of a USU on a CV, and our interviews produced accounts of very different strategies:

'If it was a big blue-chip organisation type thing I might have [emphasised it more], you know, the bigger firms, and the more I could determine that they were very supportive, I would emphasise it. But I would always mention it.'

\section{Conversely:}

'I would leave the OTC out much more for certain applications. I was very conscious of distancing myself from them because their immediate understanding of the OTC is [names a university with reputation for privileged students] based [...] and I wanted to really distance myself from that because I didn't want to be tarred with the same brush.' 
A fourth issue was the concern that recruiters would not necessarily 'have the experience of the military to be able to translate it or understand it', 'A lot of people didn't understand it really [...] the recruitment agents just didn't understand'. Furthermore, recruiters may have heard of certain USUs but not others. Placing emphasis on the USU experience also depends, then, on the idea having purchase in the graduate recruitment market. This is an issue in an international labour market, and USU experience needs to be nuanced accordingly:

'If it was a British [company] like HSBC or something like that then I assumed that they would know more about the Territorial Army and then OTC being a part of it, whereas if they were a French bank then I'm not sure if I even put it down at all.'

The reaction from international or foreign-owned companies could vary, with those based or run from the USA considered to have a generally more positive reception to the idea of military participation. Companies in other national contexts were thought to have neutral or negative perceptions of the military experience and its connection to the workplace.

In conclusion, a key determinant in shaping the use of USU experience in a job application was the career that a graduate went in to. Those pursuing military-related careers were clearly able to use the USU military skills experience to sell themselves in an application. The transferable skills element appears to have been more important for people looking for professional careers where the types of leadership and other skills practiced in the armed forces are looked on favourably. Where graduates did not use their USU experience in applications, or downplayed it, this was either a strategic choice (for employers perceived not to understand or value military experience), or a reflection of graduate perception of their USU experience in job application terms, either because it was one of a range of university experiences which developed similar skills, or because they wanted to identify their skills as separate from, rather than bound to, a military environment. For example, an individual might want to emphasise management skills but not suggest that they had a military management style, or that they had leadership skills but not suggest that they could only exercise these in a military manner.

\subsubsection{Being interviewed for a job}

Graduates were asked whether they could recall how their USU experience was discussed at job interviews. Those who said that interviewers had expressed an interest noted that it had appeared to have been viewed favourably, either as a talking point or as something that might indicate specific skills (for example, aviation-related skills) or knowledge (for example, defence-sector related skills), or as something that might spark curiosity or interest in the interviewer. 
In some cases, explaining the transferability of USU-derived skills to an employment context was made relatively easy when interviewers indicated that they had military experience themselves (and this was more common amongst our older interviewees, reflecting the wider armed forces knowledge base which National Service had produced in civilian society). Some reported that interviewers were very focused on USU experience because of a lack of familiarity with the organisation. As with job applications, graduates commented that the relationship between a USU experience and the requirements of a job had to be proven when explored at interview:

'What I'd always find was people were like "oh that's interesting, but how does it relate to [the] job?"”

But as with job applications, there were particular interviews and jobs which were assessed by the interviewee as requiring emphasis on USU-derived skills rather than the military context in which they had been acquired. USU experience could be interpreted by interviewers as an indication of maturity or indicative of life experience. For example, one graduate mentioned an interview for a job with a magazine, where 'they were very keen on my OTC experience. I suppose 'man of the world', a bit more, you know, than otherwise [...]'. In some workplace cultures:

'It was always looked [on] more favourably - that's possibly a function of working for white middle class professionals, probably purely male professionals as well, in many cases and certainly at the recruiting level.'

As with applications, there were perceptions that some organisations would be less than sympathetic to a military background. There may also be wider social attitudes towards the armed forces to consider, beyond specific workplace or economic sector responses, which were felt to shape responses to a military background.

More commonly mentioned was an experience where it was clear interviewers had no comprehension of what the USUs were. They were simply not very well known:

'I think that probably Duke of Edinburgh [award scheme] will get a tick, you know, University Officer Training Corps, not too sure'.

There were indications in interviews of uncertainty about what the USU experience might bring. Examples were given of interviewers rejecting answers to competency questions based on an OTC experience on the grounds that 'that's not really what we're looking for'. When interest was shown, this was sometimes indicative of a low knowledge base:

'They would say "oh, well I see you have been a member of the RAF reserves for the past three years, how on earth did you do that at Uni?", 
and it does show that they don't really know much about University Air Squadrons, but they were intrigued [...]'

Ultimately, graduates understood that it was an interviewee's responsibility to explain the relevance, 'because generally most people don't really understand what the Army do', so the challenge lay in being able to explain the transferability of the experience. However, in doing so interviewees then had the opportunity to discuss their skills and to focus on aspects of their USU experience which they judged interviewers to be interested in.

There was also an issue around misunderstanding what previous USU experience might mean for future career aspirations. One graduate mentioned how discussion of USU experience had to be undertaken cautiously in case this past experience was taken as indicative of a future military obligation. Another spoke of his sense of interviewers trying to gauge whether he was actually more interested in an armed forces career:

'They would look at my CV and say "oh we noticed you'd done this military leadership training, why haven't you gone on to being a full-time army?".

This issue was also raised as a potential problem in qualitative responses to the student survey (see Chapter 3) when students were asked about their prospective or actual use of USU experience in job applications.

In conclusion, it is clear that in using USU experience in the job interview process, graduates have to feel their way, reading an employer and interview panel to work out whether or not they should discuss their USU experience, and if so, how to do so. USU experience, and the transferable skills that it might develop in students which are then of use in the civilian graduate labour market, is not a solution in itself to getting a job. Rather, relevance has to be proven.

It was also clear that lack of awareness of the armed forces amongst employers, and lack of awareness and knowledge of the USUs, is quite fundamental in shaping the context where USU skills and experience can (or cannot) be discussed. This is not an issue unique to USU graduates: the work of explaining the relevance and transferability of skills derived from a military context is undertaken frequently by the thousands who seek civilian employment after leaving the armed forces, or who seek to combine their work in the Reserves with civilian employment. ${ }^{62}$ What we would emphasise here, on the basis of evidence from graduate interviews, is that the knowledge base about USUs amongst employers is low. We return to this point in Chapter 7.

${ }^{62}$ The armed forces, primarily through SaBRE (Support for Britain's Reservists and Employers), are increasingly having to explore mechanisms whereby the transferability of skills from military to civilian life can be used in employment contexts. 


\subsubsection{University armed service units experience in the workplace}

Some interviewees noted explicitly that they did not discuss their USU experience at work because, for example, 'URNU was not a particularly major part of my life at university', or because, 'I try and separate my personal and professional lives'. Not discussing an experience is of course not the same as not using the experience, and those working in international contexts were unlikely to mention their USU experiences with colleagues or clients because it could be meaningless in those contexts. Nevertheless, we were interested in whether, if at all, a USU experience has continued relevance in the workplace as former USU graduates proceed through their working lives.

USU experience might be appropriate in dealing with ex-military colleagues in terms of understanding how they work:

'I have a newish colleague, ex-Army, there's a bit of rapport, and I know he'll do what he says he'll do'.

This point is interesting because of the ways in which certain personality traits become labelled 'military', when they might equally originate in a completely different formative experience.

USU experience might also be raised occasionally in conversations with colleagues with a USU or armed forces background, or if it was known that the individual was in the Reserves. Those working in occupations where some understanding of specific armed forces roles was relevant suggested that they might share something of their USU background where this was appropriate. This came up in discussions with, for example, an engineer who worked for a commercial airline and interacted from time to time with flight crews who had military backgrounds. Interviewees who worked in the police service (which at various points in time has recruited strongly from former armed forces personnel) also discussed sharing their USU experience with colleagues. Sharing with colleagues was dependent on context.

In workplace social interactions, military-derived language or terminology could be used, or slang:

'Things like saying 'Roger' instead of 'I understand' is quite standard, which people find funny $[\ldots]$ we sort of do it in a tongue-in-cheek way.'

A former UAS graduate similarly observed that it came up in rapport with her colleagues because she now worked primarily with British Army personnel in her (civilian) job, but it was only done that way because it was just university air squadron, it's not real life - they don't see that as credible, which is fair enough. Being known as a former USU member might bring tangential knowledge ('in the land of the blind, the one-eyed man is king'). One interviewee talked of the diverse reactions she had experienced from people finding out about her OTC participation, from expressions of interest to incomprehension 
'because they think tax payers' money is being paid - we got wages to go and have fun in a field with a gun and then join the army'. It might be used as a conversation starter, or just as a quirky bit of self-revelation:

'I'm old enough to be their [i.e. younger colleagues'] mother [...] and I made some comment about diving, and they said 'is there anything else you've done?' and I just said, you know, I used to have a pilot's licence [...]'

There were generational effects: one of our older interviewees observed that in the 1950s and 1960s military service was mentioned because of the number of people who had National Service or Second World War backgrounds and ended up in the legal profession. A former UAS member who graduated in the 1980s said she rarely mentioned it because 'I don't need to make myself sound interesting any more. A former UAS member who graduated in 2010 said she mentioned it all the time. Past USU experience might also be used by workplace colleagues to explain a personal characteristic: an ex-URNU member working in advertising found that he 'can end up presenting in naval command mode', something noted by colleagues. An ex-OTC member recalled how colleagues had recognised it. On one occasion, it had come up in conversation after a busy work event when they were relaxing over drinks, and the interviewee had been seen to be taking command, having an idea about self-discipline in a public/ client context, and getting on with a job that had needed to be done.

Rather than deliberately sharing information about a USU background, in some employment contexts an understanding of specific language or communications protocols derived from that background was thought to be more useful. Individuals also mentioned their ability to identify symbolic markers (for example, a regimental tie, cufflinks and the wearing of a poppy) and to use this ability as a conversation starter or in the development of rapport in workrelated situations.

We asked graduates whether they discussed their USU participation with clients encountered in workplace contexts. Graduates were less likely to do so, but recognised that their USU background could be judiciously used to develop rapport or as an ice-breaker where it was known or suspected that the client in question had a military background. But as with workplace discussions with colleagues, graduates were cautious in discussing their past military experience, indicating awareness that it might be seen as having possible negative connotations and consequences in the eyes of others.

In conclusion, graduates suggested that the continued relevance of USU experience is dependent on context. This context includes interactions with close colleagues, with more distant colleagues or individuals encountered for a brief period in organisational contexts, and with clients. In the workplace, the ability to stand out as an individual can be useful, and to an extent it seems that having USU experience may allow former members to do so. In part, this reflects the fact that the individuals concerned may not have been anticipated to have had military experience at that age, or in that occupation. 
It was interesting to observe how, in our interviews, certain characteristics were labelled as 'military' (being a team worker, being organised and being self-disciplined), despite the obvious fact that such characteristics are by no means the sole preserve of individuals with a military background. This is notable because it indicates a broader point about how the conditioning received in a USU functions by identifying specific characteristics as military, and how that association continues on into the workplace.

\subsection{Defence-minded for life?}

A long-standing and very significant rationale for the existence of the USUs, and their maintenance through the defence budget, is the idea that the USUs develop 'defence-mindedness' - an understanding of and attitude towards defence and the armed forces which is broadly positive-which graduates then take with them into civilian life. An often-repeated idea from senior military personnel is the notion that the USUs are influential on people who later go on to achieve prominent positions in business as 'captains of industry' or in public life. We were interested, then, in assessing the continued validity of this idea.

\subsubsection{Attitudes towards the armed forces}

One of the objectives of the graduate interviews was to explore quite explicitly graduate attitudes towards the armed forces. A set of very nuanced ideas emerged from the interviews about how, exactly, those attitudes are framed and how those individuals might or might not be influential in promoting those ideas. It is also worth pointing out the diversity of the graduate labour market: the idea of training a very small elite who proceed in due course into roles with power and authority taking with them and disseminating a positive view of the armed forces may still have an element of truth, but it was notable from the interview data that a much wider set of ideas and experiences are taken into working lives, including the use of the USU experience to develop informed critiques of defence and military matters. Although one (older) interviewee had indeed been a true captain of industry in his career, a much larger proportion of the sample were younger, were not in particularly dominant positions in their sector and were speaking of the diffusion of ideas in very diverse employment contexts.

We asked quite explicitly whether being in a USU had given the interviewee a positive or negative regard for the armed forces. No-one said that their views were negative and just over one third said their views were positive, providing no further elaboration. A further one third said their views were positive and provided an explanation or further elaboration on this, with the most common explanation being that they felt they had some kind of understanding of what the armed forces as an organisation, and what individual personnel actually do. Respect for either named individuals, or for what individuals do, was a 
common theme. Graduates were also asked whether they thought their positive views were representative of other former members. Generally they did, with the caveat that positive views were held by those who had participated in their units for a period of time, and who had not left after a shorter period of experience (on which they could not comment).

There were individuals who felt that their positive view came with some kind of qualification. These were primarily to do with the culture and organisation (or otherwise) of the armed forces as an institution, with working practices cited as having negative effects, including issues such as perceptions of mismanagement. Those who said that their views were both positive and negative (who were a small number) were critical (again) of the organization and management that they had encountered in their USU.

We can infer from this that the USUs tend to instil individuals who have participated in the units with a positive regard for the armed forces. What is useful to note is the sense from interviewees that theirs was an informed view, developed on the basis of experience. In addition, a number took the trouble to point out and to qualify their statements by noting that the USU experience was something quite specific, and did not equate directly with the experience of regular personnel, particularly deployed personnel.

We also asked our graduate interviewees whether they thought they had been influential to others in terms of their positive or negative view of the armed forces. Responses here tended to be quite cautious, with very few describing themselves as vocal advocates of the armed forces. The majority of interviewees suggested that they were actually quite cautious in the ways in they might draw on their USU experience to be influential to others, suggesting that they were not setting out to change minds or influence opinion, but rather that they felt able to give a qualified view of the armed forces in contexts where the question arose and they thought it appropriate to give a view.

In conclusion, graduates tended to be positively well disposed to the UK armed forces and recognised the advocacy function that they might be able to perform for the armed forces because of their USU experience, but were cautious about the extent to which they felt they could claim expertise about defence or military matters. There was a sense from some of how little power they might have, as individuals, to shape the opinions and views of others (even if they wanted to). The strongest sense we gained from responses to this question was the idea that it was with family members and younger people that interviewees felt they had greatest sense of direct influence on the attitudes of others towards the armed forces. This might be evident in encouragement to family members or younger people to consider joining a USU, or to consider a career in the armed forces. Although there may be instances of direct, visible and pronounced influence of benefit to the armed forces from former members now in powerful positions in civilian life, the research found very little evidence that this was a common experience across the cohort. The key conclusion is that USUs graduates are influential in terms of their positive views of the armed forces in individual and quite personal ways. 


\subsubsection{Taking account of the university armed service unit experience as a civilian recruiter}

We were interested in the practical application of defence-mindedness inculcated through the USU experience. One of the ways in which we hypothesised that this might be manifest was through the ability of former USU members to understand the value or otherwise of the USU experience in their capacity as recruiters in the civilian labour market. We have already noted that there was some management of the USU experience in some contexts in the job application and interview process, and this included awareness of the lack of knowledge among recruiters about what the USUs provided. We were interested in the flip-side of that, where recruiters might have experience of USUs and how that might affect their decision-making. Ultimately, recruiters will almost always recruit according to the match between a job specification and an applicant's competency for the role (and equalities legislation and human resources practices ensure this). We were therefore not expecting unfair advantage to be manifest. Rather, we were interested in how pre-existing USU knowledge might be handled by recruiters, given what we have observed about graduates' negotiations of their USU experience in their own job-hunting practices. About one third of our graduate interviewees had personal experience of recruiting in the civilian labour market or for social organisations, so spoke from direct experience. We did not restrict questioning to just USU experience, so we have also included comments made about the recruitment of former armed forces personnel.

Former unit participants who, as we have already indicated, tended to have a fairly positive view of their own experience, were ready to show an interest in someone with a background which they could recognise. USU or armed forces experience was not the only activity where this was pertinent, but it was significant:

'I've done a lot of recruiting in my career, a lot of interviewing, a lot of recruiting graduates as well, and I'm always interested in anyone who's been in the OTC $[\ldots]$ or Territorials, that's a very positive interest. I'm not saying I would give them preference but its certainly a big influencing factor - the fact that someone at the university has got off their rear end to go and do something, I think that gives me a good indication of the sort of person that might be.'

'I've always looked favourably on people who've had a military background, and the reason for that is, generally speaking, they tend to be hardworking, they tend to be diligent, what they perhaps lack in some cases in imagination they make up with good strategy'

The individual quoted above noted how she had 'seeded' people with military backgrounds into teams, not specifically because of some kind of trained ability 
for teamwork, but because in her view good teams needed different types of people- and as a type, those with military backgrounds had recognisable roles and thus a positive effect on their team. An individual who recruited volunteers for a youth organisation made a similar observation about his experience in recruiting someone who, despite personal differences, he felt he could understand in terms of how this individual worked, because of the individual's military background and our interviewee's experience with the URNU.

An individual who ran his own software company commented that he would be more inclined to look favourably at a CV showing USU experience, because having established a person's technical ability to do the job in question, there was a very significant question of whether the potential employee would fit with the team. Getting them to talk about their military background at interview was a useful way of providing someone with the opportunity to demonstrate their attributes: 'actually it's a question of "are we going to get on? Is the team going to work well together?"'.

The idea that certain skills or abilities might be associated with a military background was evident:

'When I joined [the police] there was a large tranche of NCOs [...] you do tend to find they make really good policemen - there must be something in certain aspects of people from the military fits in well with it. [...] it's a discipline job.'

One interviewee talked of the 'phenomenal' abilities she had encountered in ex-forces personnel in terms of logistics and project management, areas she saw the Army as excelling in anyway. Another with a career in higher education administration found ex-service personnel 'business-like, efficient looking, and they tended to know stuff'. An interviewee saw former forces personnel as 'more organized, calmer'. An assumption about abilities for teamwork was also noted.

Although this was seen in some circumstances as advantageous, there were cautions and caveats. The individual quoted directly above also noted that in his profession, air traffic control, he was aware that although former RAF members were seen 'in a certain favourable light [...] they often don't transition well to the role'. An interviewee with a long career in the public sector, including in defence-related activities, drew distinctions between ex-military personnel on the basis of rank. He said he had developed a view later in his career dealing with very senior military personnel which 'unfortunately wasn't very positive'. Military personnel constantly moved jobs, roles were often narrow and:

'[...] it's a different way of working in civilian life - I think you behave as if you are there forever [...], that you would expect to see the consequences of your decision, one had the sense with the military that [...] there wasn't the sort of holistic responsibility that I expected of managers.' 
Deference and an expectation of working in a hierarchical culture meant that there were adaptation issues, as was the (in)ability of senior officers in civilian roles to develop concepts and innovate at a strategic level. However, there was the opinion that their ability to manage real time changing situations was well developed.

In conclusion, there was nothing from our interviewees to suggest that former armed forces personnel or people with a USU background receive an unfair advantage, but in some contexts that background could be advantageous.

\subsection{Considering a career in the armed forces}

None of the graduates we interviewed had pursued a military career. With a cohort of the diversity that we had, there were inevitably a wide range of structural labour market factors and recruitment contexts shaping career choices and the question of military participation (and for a couple of our interviewees, this was not optional as they had been required to do National Service). Beyond this, we were interested in whether these individuals had at one point intended to join the armed forces, and the reasons why they did not. It is worth reiterating that the sample contained successful, educated people who would be attractive recruits for the armed forces, so we were mindful of the potential utility of the graduate responses we received.

\subsection{1. 'Try before you buy'}

Roughly one third of our graduate interviewees said that they had entertained the idea, at some point prior to or during university, of entering the armed forces. This figure corresponds with that in section 3.6.2 above showing student intentions with regards to an armed forces career. This included those with childhood aspirations (fighter pilot is a common one), and those who had given the idea no consideration at all until participating in a USU at university. Of these, a small number proceeded with applications to commission into the Army, RAF or Royal Navy, but either failed to meet the required standards or decided to follow another career path. A number of comments were made to suggest that during their time in a USU, the armed forces had been far less proactive about using it for recruitment than was perceived to be the case at present. The remainder determined through their USU experience that a full-time career in the armed forces was not for them, and for a variety of reasons. This seems a highly significant beneficial effect of the way that USUs are organised and structured, around voluntary participation: the value of the USU experience, for many people and for the armed forces as organisations, was felt to be that they provide a space for potentially interested recruits to the armed forces to determine whether or not a career in the armed forces is actually right for 
them, and if so, in what capacity or role. In the words of one interviewee, USUs provide the opportunity to 'try before you buy'. In a number of cases, individuals who had intended to proceed to officer training before joining their unit but ultimately did not, were thoughtful about the benefits of the USU: by joining a unit and deciding not to pursue a military career, they did not then become either dropouts or rejects from an officer training programme, or disgruntled or ineffective officers once commissioned.

When reflecting back on their personal contribution to the units, there was a sense from many interviewees that by participating, both they and the armed forces had the opportunity to establish whether or not that individual had the potential for a career in those forces. A good example of this came from an individual who, by his own measure, had been highly motivated to join the RAF on graduation, and indeed had been in receipt of a bursary whilst a student in recognition that this was going to be his likely post-graduation destination. Yet he said that he had found himself getting more and more frustrated with the RAF whilst in the unit, and in turn, that the RAF through his UAS participation had had the opportunity to vet him, and in the process had found that he was not right for the organisation. Another noted that he had suggested to people (who were not in an OTC) who were keen to join the Army to try the OTC first, saying that he had been 'sort of the opposite of a recruiting officer to people who say they'll join the Army. I say "go along to the OTC and see if it's actually going to turn out how you think"'. One interviewee likened the unit experience to a two or three year job interview, an opportunity for screening applicants.

Although ultimately these graduates decided not to join, what we consider significant in reviewing the interview data is the idea that one of the greatest benefits of the USUs is the opportunity it provides for carefully considering a pre-university intention to join the armed forces. By being able to 'try before you buy', these individuals could experience military life without having to commit, and were able to use that opportunity to enable a decision to be made with huge potential consequences for subsequent careers. The value of the USUs, then, may well include unit abilities to shape recruitment by dissuasion (again, echoing the comments of current students in section 3.6.2. above).

\subsubsection{Push and pull factors and career choices}

The remainder of interviewees provided a range of explanations as to why they had not pursued a military career, ranging from lack of interest, medical issues, personal circumstances and family commitments, to the availability of more attractive alternatives. In exploring why a group of people who overwhelmingly indicated that they had enjoyed their USU experience had determined that a full-time career in the armed forces was not for them, explanations can be categorised as 'pull' factors (the attractions of a civilian career and life) and 
'push' factors (features of the armed forces and a military life which dissuaded individuals from a military career).

Pull factors were quite straightforward: individuals wanted a career in a particular sector, or to pursue an occupation where opportunities were limited in the armed forces, or to use their degree more directly. Interviewees, who as we have noted were all highly educated, and largely a dynamic and highachieving group (judging by their maintenance of professional careers), had higher aspirations than a career in the armed forces was perceived by them to afford. A number explained that their younger selves had been ambitious, and more ambitious than a career in the armed forces could accommodate. It seems that the very thing that is celebrated as a quality required in USU participants, that dynamism, get-up-and-go, the urge to achieve and to do something different, is also the thing that pulls many away from a career in the armed forces. Whether this is perceptual or actual seems beside the point; the fact is that the armed forces were seen by many as offering limited career opportunities to bright graduates.

The push factors, things that actively deterred USU participants from considering an armed forces career, were more complex. A small number cited medical reasons, that is, they would not have passed the required medical tests for commissioning into the armed forces (or at least for the specialism they were interested in). The remainder cited perceptual issues, and the following were cited either singly or in combination.

The lifestyle demanded of a career in the armed forces, including the perceived impact of that lifestyle on later family life, was key. The articulation of reasons against joining on the grounds of lifestyle were about potential, perceived future aspirations. There were those who cited issues such as the lack of appeal of barracks life, of being told where to live and/or of continued personal mobility. One talked of wanting to live in a particular geographical area. Another wanted the option of not going to war, if required. Then there were those who cited lifestyle in terms of aspirations towards family life. This was expressed in terms of wanting to have children and to get married within the context of a civilian home life, a perception that a military lifestyle was incompatible with family life, and a perception that the mobility required of a military career would potentially have a detrimental impact on a spouse. With graduates whose partners had also been in units, the idea of them both being in the armed forces was seen as impractical in terms of being able to spend sufficient time together because of demands (in the case of the Royal Navy) to be away at sea, or because of the demands of a period of deployment. We would note at this point that these ideas are not specific to graduates; the point, however, is that it may be during USU participation that these ideas become consolidated.

Graduates also talked of their own limits, of using their self-awareness as a factor determining their decision not to pursue a full-time military career. Examples included wanting variety in a job, and perceiving (in this case) a job in the RAF as restricting choices, keeping that person doing one particular 
thing. Individuals noted their levels (and lack of) of self-confidence and maturity at the time. One spoke of not having the requisite intelligence ('I would have found it hard to keep up with the syllabus'), and another noted that other people were better suited to such a career.

The culture and class structure of the armed forces was mentioned by a small number. One individual perceived that his failure to pass through the (Army) Regular Commission Board was class-based: he felt that he had been treated differently because of his class background and noted how bitter he had felt at the time. Another mentioned his perception of male chauvinism prevalent in the service to which he had applied, which he found distasteful ('I didn't like what came out of Sandhurst'), and felt he would have found living and working with such people intolerable. For others, it was simply not wanting the military discipline, authority, the command structure or to be working in such a structured hierarchical environment.

There were also the limitations of an armed forces career, particularly at various points when the armed forces were contracting and opportunities were seen as limited. Three women also mentioned that restrictions on the employment of women in place at that time had meant that there were no desirable jobs open to them, or in one case, an instance where her corps of choice (the Royal Engineers) had only just started taking women, and she did not want to have to deal with what she perceived as the challenges that would follow by being in the first cohort of women in that corps.

For the interviewees who had Reserves experience, there were useful insights in responses to the question as to why that individual had chosen not to pursue a full-time career in the armed forces. For example, whereas the lifestyle associated with full-time participation was perceived as unattractive, the ability to combine paid civilian employment with Reserves participation, and thus take a further step having participated in the USU, was significant. One interviewee, for example, noted how attractive the Reserves had been as an option as a good break from his daily working life, though he felt that doing it full-time 'would ruin my hobby'. Another noted how he had joined the Reserves in preference to the Regulars because he wanted a home life. Also mentioned were ideas about being able to keep a distinction between a civilian occupation and a Reservist role; an interviewee discussed how he enjoyed the hands-on aspect of his work in the Territorial Army (TA) in contrast to his desk-based civilian job.

In conclusion, there was a diverse set of reasons why the graduate interviewees had not pursued armed forces careers, around push and pull factors. It should also be noted that a number talked about how the decision ultimately was quite circumstantial, with the arrival of a job offer from a civilian employer at a specific point in time being the determining factor, although the choice between a military and civilian career option had been a close-run thing. There was also a sense from a number of interviewees of an element of chance, with the idea of joining the armed forces fading away as the person ended up pursuing something else, rather than the individual making a deliberate decision not 
to join. Generational differences were also evident, with people graduating in the 1990s quite possibly facing a different labour market than those in the later 2000s. What was evident, overall, was that reasons for not joining can work in combination. People make choices that are rational at the time. Some people do not have a single reason that they can articulate. We were also aware whilst interviewing that the explanations that people give for past choices and decisions may change over time, with the benefits of hindsight.

\subsection{The value of the individual to their university armed service unit and the armed forces}

The schedule used to interview graduates who had participated in the units as students focused primarily on the detail of the value of the USU experience to that individual. However, we also asked individuals what value they, as individuals, might have brought to the armed forces or the USUs. This was an interesting question to ask because it provoked considerable thought on the part of interviewees. The responses, however, could be categorised quite clearly. We have not attempted to quantify these and many individuals made several points in response to this question. The purpose of the analysis here, given the qualitative nature of the material, is to provide a sense of the range of ideas forthcoming in response to this question, because they suggest some additional issues pertaining to questions about the overall value of the USUs.

\subsubsection{Tangible benefits to the armed forces}

In responding to a question about their value to the armed forces as individuals, there was a good sense from interviewees that the investment of defence resources in them whilst they were USU participants could reap tangible rewards for the armed forces further down the line. Those rewards might be incidental, and when expressed as single examples may seem very modest. Cumulatively, though, they point to a return on the investment.

The practical effects of the knowledge that individuals gained about the armed forces, and about individual services and their functions, was cited as a range of small examples indicative of a broader process of practical assistance. Examples included: providing a civil servant with experience which helped her deal with military colleagues in her job to the advantage of those colleagues through her understanding of rank, manner and organisational culture; a logistics manager working in air transportation using his UAS experience to assist with outsourced elements of the Army supply chain; a marketing manager working in public relations and using their USU experience in developing a customer relationship management strategy for an armed forces account; a police officer alert to the specific issues that might affect veterans encountered 
in the course of his duties (including, for example, knowing that a claim of status as a veteran could be very readily tested by asking an individual for their service number, something this individual understood was never forgotten) and another member of the police service able to use knowledge to assist with local military ceremonial events. Included amongst the practical benefits to the armed forces were instances of assistance to USUs. Examples included: an air traffic controller able to facilitate his local UAS's flying training by management of landing slots and airfield use costs; an individual with accountancy qualifications able to assist with business processes for his local OTC unit and a former UAS member now working on a voluntary basis as a flying instructor for the Royal Auxiliary Air Force:

'I've put back a thousand-odd hours of flying instruction and I got 100 hours out of them as a University Air Squadron member - I've now given an order of magnitude more than that back to the next generation of Air Cadets. I'm doing that on a volunteer basis because it feels worthwhile, I owe them some debt and because I enjoy it, I want to pass on some of that enthusiasm to other people. So in my case I suspect that's the most tangible benefit.'

There was also benefit in the simple fact that the service units comprise a body of people, in uniform, to be deployed for assistive tasks, such as playing the enemy for military training exercises or able to (quite literally) fly the flag for the armed forces. In the words of one former URNU member:

'They got my hands for free, or at very low cost. We went around the coast flying the flag. It would have been very difficult for the military to have been able to pay for a patrol boat to go round and do those particular public relations jobs we did without having cheap student labour driving them.'

Another URNU member noted that:

'I manned a P2000 going round British waters showing the flag to parts of the UK that don't see a grey-hulled warship. It's difficult to justify paying full-time naval personnel to do that kind of exercise when the Navy is otherwise overstretched. We would open the ship to the public [...] beat the drum for the Navy. [...] I remind my fellow [professionals in a maritime-based occupation] that the only reason they can safely go around the world taking measurements is that there's a Navy there to protect you from all sorts of things - the fact that there's piracy still going on these days means that you need the Navy and without it you couldn't have a nice slow-moving research vessel safely pottering around the place to do the business. For my own community's point of view, I don't mind trying to remind people of that very important fact.' 
In conclusion, with the exception of one former UAS member who had gone on to work at a very high level in defence procurement, our sample of interviewees did not really match the anecdotal figure of the captain of industry, using his or her authority at a senior level to influence either the business of a company or employees in that business in ways that would be beneficial in some way for the armed forces. Rather, the evidence collected showed individual acts, sometimes incidental, sometimes occasional and sometimes more day-to-day, which in turn could 'repay the favour' of an initial investment in an individual. This is significant because it suggests nuance and unpredictability to the benefits accrued to the armed forces (and the defence community more broadly). Investment in individuals through the USUs is, in a sense, a leap of faith on the part of the armed forces. That this investment continues reflects a tacit understanding of this within defence, based on decades of experience.

\subsubsection{Intangible benefits to the armed forces}

We noted above how the USU experience had given participants a generally positive attitude towards the armed forces, and have also noted how that attitude might translate into practical activities. What was also evident in talking to former participants about the value of individuals to the units was the role they might play as advocates for the armed forces.

This advocacy might be evident in a variety of different situations at different times. Examples included: support given (in time and money) for armed forces charities, encouragement individuals might be able to give to younger people about the benefits of an armed forces career, being involved in public remembrance events or being able to include consideration of the armed forces in public educational events. The idea of being an ambassador for the armed forces was often mentioned:

'I can point out the value and professionalism of the armed forces.'

'They've got a positive advocate, someone with an appreciation for what we are trying to do and why.'

'I'm able to correct people's misconceptions about the military and what they do.'

A few individuals made the point that precisely because they did not think they were perceived as military types, or according in some way with a cultural stereotype of what the armed forces represent, that this was of value:

'I can go out and promote what the armed forces do, with my peer group, friends. I'm a Guardian-reading, go-on-strike fire-fighter - I'm on the other side of what a lot of people are, I can see the benefit of 
having an armed forces system. I'm not right-wing, I have a liberal point of view, which can be beneficial.'

In conclusion, the mechanisms for the translation of positive attitudes toward the armed forces through advocacy or ambassadorship were often low-key, incidental, seemingly prosaic and were mechanisms used with friends or family, or in occasional encounters. Again, the captain of industry model seems a little outdated for this mode of communication, but the substance of what interviewees said is significant because it speaks to the intangible (often nonquantifiable) benefits of the existence of the units.

A further point to note here is (again) the caution expressed by graduates about the extent to which they could claim expertise and thus incur influence on the basis of their USU experience. There was considerable awareness of the inadvisability of over-claiming experience, expertise and thus influence.

\subsubsection{Socialising the armed forces}

A small number of interviewees raised the very interesting issue of the extent to which the USUs serve to 'socialise' the armed forces, specifically the Regular forces. We use the term socialise to refer to activities and attitudes which work to connect the armed forces to a set of wider civilian cultural practices. ${ }^{63}$

In terms of what they might have brought to their units as individuals, some interviewees made the point of stressing what they as students brought which was distinctive. One, a mature student at university and thus the oldest officer cadet in her OTC, thought that she had demonstrated through her presence and her contribution a valuable point for the unit's command and training team that it was indeed possible to recruit mature students, and that units could get something quite specific from them in terms of an individual with some life experience, which she considered to be helpful for the younger students in the unit. Another (a graduate from a plate glass university founded in the late 1960s) thought that the inclusion of people like her who did not come from ancient or high-profile, long-established institutions gave the OTC an understanding of the different backgrounds that officers could come from, in addition to the way in which the unit experience provided an opportunity for people from less prestigious educational backgrounds to prove themselves. Another talked about how, with a group of people like herself who knew that they did not want a military career, they:

${ }^{63}$ This idea resonates with observations within military sociology, that military forces in many ways operate according to distinct cultural codes and practices which reflect their specificity and social distinctiveness as a group holding state-legitimized authority to execute lethal violence. 
'[...] kept it real for them. Not everybody is obsessed with three letter abbreviations and doing everything military style, we kept it so it didn't become a recruitment facility, kept it as a university club with a bit more purpose.]

For the officers and Other Ranks in charge of her unit, 'it was interesting for them, we were a bunch of students, had that headiness'. An URNU member observed that for Royal Navy members with organisational responsibility:

'[...] it's an interesting posting for them, working with a bunch of students who don't follow orders, are always questioning, being fairly irritating - I hope it was positive for those guys, certainly different from what they did previously and did afterwards, hopefully it gave them some benefit.'

Another noted how her UAS brought life to the officers' mess at the facility where they trained, that it was refreshing for the military to have 'young blood'. An OTC graduate spoke of how:

'[...] we used to get interesting Sergeant Majors who thought they'd come to the posting for a couple of years off, but they wanted to stay, they really enjoyed working with the students, it was a learning experience for them, working with us.'

So whilst those in charge of the units might have "had days where they queried why they accepted the post' because of student rowdiness from time to time in the mess bar, it also made for an interesting posting. Students 'annoy the living daylights out of Sergeant Majors and Sergeants everywhere. Yet it was notable how so many former USU members spoke of their COs and training staff with warmth and respect.

We would not want to overstate the case about the socialising effect of the units on the wider armed forces. This would appear to be an incidental consequence. However, there is a wider point to be made here about the value of this, given the context for the contemporary British armed forces where debate continues about the level of connection between civil society and the military; this connection is, of course, a two-way street, an idea often missing from commentary about the issue.

\subsubsection{Recruitment to the Reserves}

A visible, material and distinct benefit to the armed forces, in the view of former USU members, was their post-graduation involvement with the Reserve forces. As noted above, a considerable proportion of the sample had some kind 
of relationship with the Reserves, and for the majority this developed after graduation. This was a clear and direct value to the armed forces of an individual's participation in a unit:

'They benefitted considerably - they had a very competent TA officer, very energetic, enthusiastic, conscientious.'

'They got a Reserves officer for $15-20$ years. I didn't break anything expensive [...] I think they got their money's worth out of those three years.'

'They got 12 years of service, involved in officer training with other officers, conducted operations, kept continuity in the regiment as senior reserve officer, helped with corporate memory of the regiment, helping with [a high profile international sporting event] with communication support, they certainly got their pound of flesh.'

'As an individual their investment in me was tremendously well spent, in terms of national budgets. Much better than attacking Iraq. It's not a simple question. They got my technical abilities - working intelligence in the TA, I could fire a $25 \mathrm{lb}$ gun. They got my academic abilities in geography, surveying, linguistics, photographic interpretation [...]'?

'They got 20-odd years of me in the TA as a communications manager in [regiment], making a contribution during the floods in Cumbria $[\ldots]$ the firemen's strike, helping with the G8 summit in Northern Ireland. I've given something back, and bring on individuals from the next generation.'

What was illuminating in the interviews were the number of critical comments made about the proactivity or otherwise of either the parent services or the units themselves in encouraging individuals, at the time of graduation, to think seriously about a future with the Reserves. These comments reflect recruitment practices at the time in which individuals were getting ready to leave university, and so varied over time. What was evident and notable were individuals' regrets, looking back, that they had not taken further steps towards the Reserves. Two significant points emerged from this discussion. The first was that graduates themselves noted that in the two to three years post-graduation, during which they were busy with new jobs, possibly involving additional training, possibly involving relocation, and also new relationships and activities, the sheer busyness of their lives made it easy to lose sight of the Reserves as a possible activity. Once they had undergone the transition from student to worker (a process that takes time), a number reflected that it would have been at that point (rather than immediately on graduation) that they would have been most receptive to the idea of Reserves participation. The second point to emerge in discussions followed from this: graduates reflected that the armed forces themselves could have been far more proactive in keeping in touch with their alumni specifically 
because of their potential receptivity to the idea of Reserves participation. We return to this point in Chapter 7 .

\subsubsection{Sustaining the university armed service units as organisations}

Evident in the comments of interviewees both in response to a direct question about their value as individuals to the armed forces, and in responses to other questions about their activities in their unit, was the idea that the units are, in certain respects, quite self-sustaining. A large proportion of respondents talked about how enthusiastic they were as student participants. This enthusiasm is not an insignificant issue for the units, of course: unit participation for the majority is voluntary rather than necessary, and a unit which does not provide an experience about which people can be enthusiastic will of course struggle to maintain its numbers.

But more significantly, it was evident how this enthusiasm was seen by participants to translate into practical activities and input. Examples include: organising a rugby tour for the unit squad to the Czech republic, helping organise a UAS squadron as acting pilot officer, organising social events ('some damn good socials!'), bringing on younger students through mentoring and support, organising adventurous training, helping with recruitment, assisting with the organisation of unit attendance at public events and assisting with publicity ('they got a fantastic website'). We have already noted how the USU experience provides for many people an evidence base for claiming competency in particular skills in the job application process. Some of these skills, particularly organisational, recruitment, managerial and business-related skills, may have been noted by individuals primarily for the edge that it might have given them in the labour market; there was also a strong sense that the flow of value or benefit in the USUs was not one way in favour of students, but that students were in a good position to give something back to the organisation through their work with the units.

In conclusion, whilst we did not set out to provide a cost-benefit analysis of the value-for-money of the USUs, one of the benefits to units that was apparent (at least in terms of graduate explanations) was the value of the labour expended by student participants in the organisation of activities of the unit. It is these activities which are the prime draw of the USU experience. Some of these activities require trained, experienced staff to facilitate them. But a lot of them do not, particularly sporting and some adventurous training and social activities. We suggest that the units are more self-sustaining than they are often perceived to be. They may require funding from the defence budget in order to exist and function, but in many ways that investment is very well targeted at meeting quite specific costs; student labour may not be entirely free (because participants are paid), but the value of that labour can be very high in terms of contributions to the unit. 


\subsection{Graduate perceptions of the value of the university armed service units}

At the start and conclusion of each interview with USU graduates we asked them a very broad question, which they could answer in any way they chose, about what they thought the value of the USUs is, was or could be. Many of these ideas were then rehearsed in the body of the interview, and are evident in the sections above. They bear possible repetition here because in collating them, a very distinct picture emerges about who benefits from the USU investment, and how exactly that might be defined.

\subsubsection{The personal value and individual benefit of university armed service units participation}

The dominant response of graduates to the question about value was to emphasise value to themselves as individuals. This personal or individual value was manifest in multiple ways.

The USU experience was seen as valuable in individual terms because of the opportunity and structure it provided for the development of capabilities of the self and of personal attributes. These included self-discipline, perseverance, facing and overcoming challenges, resilience, determination, drive, selfconfidence, self-awareness, self-knowledge, an ability to work under pressure, self-respect, independence and initiative. Some of these personal qualities were recognised as having reach beyond individual benefit, and included: being able to act with responsibility and being willing to take on responsibilities, respect for others, the ability to undertake collaborative work, the ability to consider issues from different perspectives and a sense of moral and social responsibility and commitment (the idea of putting oneself out for the benefit of others).

Specific skills and abilities were also a value of USU participation. These included leadership, teamwork, communications, problem-solving, making presentations, time management, liaison and organisational skills. The correspondence between this list, and the list of graduate-level skills discussed in Chapter 3 is evident. Some practical skills were mentioned, such as driving and catering for larger numbers, but primarily in terms of skills it was the transferable skills which were of benefit.

The development of personal attributes and transferable skills in turn had value in leading to paid employment. Graduates highlighted how attributes and skills contributed to their CV, and how the USU experience might be understood as bringing something a bit different, lending distinction to a CV. The experience was thought to help in performing a job and encouraging a positive attitude at work, notably in developing an attitude of getting on with things. It was viewed as instrumental in raising aspirations and giving individuals such as young students an awareness of the possibilities they could entertain in terms 
of their personal career goals. More practically, it provided an insight into the working world and into different kinds of jobs and occupations, and gave students an experience both of managing and of being managed in the workplace.

In terms of non-military activities, the USUs provided opportunities for improving physical fitness and for engagement in sports. Otherwise quite expensive leisure activities, such as skiing, were made affordable. Activities unavailable either in civilian life or through other student societies were of individual benefit, including opportunities for travel both within and beyond the UK.

The knowledge and understanding that individuals gained of the armed forces on the basis of their USU experience was of individual value because it gave individuals the ability to get what they wanted out of the experience. The armed forces were organisations which nurtured skills, talent and potential, and this was part of the way in which the experience of USU participation developed positive views of the armed forces. This was coupled with education and increased awareness of armed forces roles, responsibilities, organisation, function and structure. The unit experience encouraged people to keep up with current affairs, and could be influential on an individual's political views.

The USUs offered a very valuable opportunity for individuals to assess whether an armed forces career was the right choice for them. Participants could experiment with the idea of joining in order to assess their 'fit' or otherwise with the armed forces, and the units offered a safe and controlled environment in which to develop that decision, including having units act as a safe place in which to make mistakes. The units provided an opportunity for potential recruits to identify a suitable career path within the armed forces. The units also provided exposure to different types of people within the armed forces themselves, such as NCOs, and a socialisation experience within the armed forces prior to joining.

The social life offered by the units was identified as important. Ideas articulated by our interviewees included meeting new people and mixing with a range of other people, including different types of people that an individual would not otherwise have an opportunity to engage with, such as those beyond an individual's degree programme cohort; the units broke down the insularity of degree programmes. Interviewees mentioned camaraderie, the familial relationships within units and the ways that units generated tolerance for other people. Units enabled students to develop a sense of identity whilst at university, particularly during the first stages of the first year, whereby they gave students a feeling of being part of a group and provided a support network whilst at university. Participation was fun, 'like glorified Scouts [...] but with beer' in the words of an interviewee, and although there was caution about seeing the units as just a type of social club, there was clearly fun to be had.

Unit participation was valued because for many it gave a sense of purpose whilst at university, grounding them, giving them a sense of a reality beyond what one respondent termed 'the university bubble', keeping students on track with their studies and providing a structure to the university experience. The 
experience was seen as prompting students to put greater effort into their academic studies because of the unit emphasis on teamwork, leadership and time management, and some observed that the skills learnt through their unit experience were transferable to the skills required to succeed in an academic programme.

The income received through unit participation was a value. The USU experience may be more fun that bar work and brought the rewards similar to a part-time job in terms of remuneration:

'The money influenced me slightly because I was paid, I couldn't have afforded to do it if I didn't get paid.'

There were a small number of critical comments about the social mix at the units, with the dominance of people educated in the private (fee-paying) sector being noted. That said, a number of women mentioned the benefits of unit participation that they felt they had received as women. Being able to engage in adventurous training opportunities was significant. One respondent made a very interesting observation about how, as a woman in the OTC, it was one of the first places that she had seen real gender equality, which she'd found surprising and 'eye-opening' given the Army context. She commented on how it had been 'amazing' to see team members work as team members if one was struggling. This idea had stayed with her:

'I've never yet been in a role or a job where men and women [have had] an equal playing field. So it was really interesting to see and I think that's really stayed with me.'

In conclusion we would emphasise that the USUs are not the only student activities where these individual benefits can be accrued. Our respondents attributed these individual benefits to their USU experience in response to questions about that specific experience, and we did not explore other student activities and their benefits during the interviews (and there would certainly be room for a comparative study on this). The key point here is that for our graduate interviewees, a key aspect of the value of USUs is the personal and individual benefits that participation brings.

\subsubsection{The value of the university armed service units for the armed forces}

Although not mentioned with the same high frequency as the individual benefits identified above, interviewees articulated a number of different reasons why the USUs had value specifically for the armed forces. Again, we have made no effort to quantify responses here, but rather show the range of ideas articulated across the sample. 
Just as there were individual benefits in terms of understanding the armed forces, the armed forces themselves were perceived by graduates to draw value from the units as vehicles for enhancing knowledge, and many of the responses mirror those above. The recruiting function the units served for the armed forces was key here, as the armed forces were seen as having a tacit or implicit opportunity to assess whether individuals had a potential future with them, and could provide contacts for individuals with specific branches within the armed forces. The units were an opportunity for the armed forces to encourage people who had not previously considered an armed forces career, and provided a good introduction to the Reserves, generating good officers (although this comment was also made with the caveat that there had been scope for greater proactivity by the armed forces in encouraging recruitment to the Reserves in the past). The armed forces could 'weed people out' of the recruitment pool. The armed forces also benefitted through the utility of unit participants being influential on others either joining a USU or the armed forces. The units were increasingly significant for recruitment of trained officers for the Reserves, with one interviewee who was a Reservist noting that his regiment relied on the OTC for direct entry officers to his regiment because of difficulties in recruiting.

The armed forces were thought to benefit through the increased public understanding that USUs generated in people who would not go on to join, and through the generated empathy, affinity for and insight into the armed forces. The units gave individuals a fuller picture of the armed forces beyond a 'glossy public image, a fuller understanding of military roles in political and international situations, and an understanding of both day-to-day activities and the more theoretical or abstract roles. At a time of contraction of the armed forces, this was thought to be important. Insights developed into the organisation were valuable, and the broader understanding units helped develop of the armed forces was significant because members might become influential in later life. The units also provided opportunities for cross-national and cross-cultural understanding of other national forces. There were also practical benefits in terms of the availability of additional personnel (unit participants) for emergency response activities, and were thought to enhance the capacity of the Reserves. The question was raised, however, about how quantifiable these benefits might be.

The value to the armed forces was also evident because units might have generated sympathetic employers with a positive attitude towards the armed forces. They may have enhanced the public visibility of the armed forces in general, and in university contexts, and stopped the armed forces becoming too insular through student engagement with those forces and enabled networking between the military and civilian worlds.

A very small number of respondents talked about their perceptions, as students, of how sometimes the units were viewed by personnel from the Regular armed forces in a negative light. One noted how this might reflect an atmosphere of concern about wider issues affecting the armed forces, particularly redundancies and budget cuts. 


\subsubsection{The wider social value of the university armed service units}

Although far less frequently identified as a value of the USUs, the units were thought to bring wider social benefits beyond the value to individuals and the armed forces. The idea was articulated (rather similar to the idea of the value of a university education) that employers, and thus the wider economy, benefitted by having individuals with an enhanced set of skills and experience. Having educated, successful and knowledgeable people in the workplace was a societal advantage. As one respondent noted, he had spent 12 years working in transport infrastructure 'taking half the people' in a major city 'to work and then home again'. He judged the air squadron to have been instrumental in setting him on a path which led to that job, and creating someone contributing to society.

The USUs, it was thought, 'produced better citizens' and brought social benefits through the units' inculcation of a sense of discipline in individuals, rather like National Service had. More broadly, the units enabled the bonding of the military into civilian social life.

Universities were thought to benefit by producing 'better graduates', and the link between education and the military was thought to be useful, with student participants bringing qualities, ideas and experiences back to their respective universities.

The units were mentioned as enabling social mobility, although this might be era-contingent. What was significant here were the opportunities the units could provide to students, particularly those educated in the state sector or from backgrounds of modest means, to participate in extracurricular activities otherwise not available to them. Similarly, the units provided access opportunities for women to activities that might otherwise be less available to them; an example was cited of the UAS training women pilots before the RAF.

In conclusion, although the wider social benefits of the USUs may be identified, this was not a primary source of value of the units in the experience of graduates.

\subsection{Conclusions: the value of the university armed service units to graduates}

The sample of graduates interviewed for this element of the research was a diverse one in terms of interviewee age, educational background, career and work experience, and USU participation. This reflected the aim of the sampling strategy to generate data on a wide range of experiences. The point of qualitative methods, such as those used for exploring the question of USU value amongst graduates, was not to seek representativeness in the sample, but rather to explore the diversity of experiences in order to enhance understanding of the role of USU experience through post-university life. This diversity of experience is reflected in the responses, although certain key findings emerged. 
In terms of the value of the USU experience to graduates in the workplace, there is utility in the citing of that experience in job applications and throughout the process of getting a job. However, this utility has to be proven by the individual and cannot be assumed, not least because of the absence of knowledge about the USUs amongst many employers. The potential attitudes of prospective employers to military experience also has to be carefully negotiated. The utility of the USU experience may be useful in the workplace, often in quite modest ways, and there is evidence of utility and value to the armed forces as a consequence of the presence of individuals in the civilian labour force with USU experience. It is notable that the significance of USU experience in job applications is greatest in the first two to three years following graduation, giving graduates a set of experiences and evidence of skills that are beneficial in the job application process, but which are superseded as careers progress with the development of civilian workplace experience.

In terms of the USU experience generating defence-mindedness amongst a group who go on to pursue civilian careers, and this is the great majority of USU graduates, the USU experience develops and instils a positive attitude towards the armed forces. However, graduates are cautious about claiming any specific expertise on the basis of their experience. They may be modestly influential to others in terms of family members and younger people with regards to transmission of attitudes and endorsement of the USU experience. This positive attitude is reflected in attitudes towards the employment of others with an armed forces background, within the parameters of equitable practice.

In terms of the utility of the USU experience in shaping attitudes towards a career in the armed forces, there was strong endorsement of the idea that the USUs serve a positive role in establishing, for both potential recruits and for the armed forces, the suitability or otherwise of an individual for such a career. The graduates, on the basis of their USU experience, had illuminating points to make about exactly why they had chosen not to pursue an armed forces career, emphasising both factors which had pushed them away from those career pathways and factors which had pulled them away towards other career options. This was despite a significant proportion (about one third) noting that they had entertained the idea of an armed forces career whilst in their USU.

In terms of the value of individuals to their units, points where made which were illustrative of the function of the units. There may be tangible benefits to both the USUs and to the armed forces in terms of things which individuals may be able to contribute, or an individual's utility may be manifest in more intangible ways through their advocacy of units and the armed forces. The USUs were thought by some to be a mechanism for the socialising of the armed forces. Individual returns on the investment in them through the units could be evidenced through those individuals' activities in the Reserves. The point was also made about the value of student labour in sustaining the activities of USUs.

In terms of the overall value of the USUs from the perspective of graduates, this was to a significant extent thought to be manifest in individual benefits. 
These benefits were in the form of the USU experience providing opportunities for self-development, the development of transferable skills, enhanced understanding of the armed forces, information to inform a decision on whether an armed forces career was appropriate for that individual, the experience of a good social life, the provision of an experience in addition to academic study whilst at university and of course, the benefits of being paid whilst a student. There was also thought to be value to the armed forces, again in terms of establishing the suitability of USU participants for careers in the armed forces, whether Regular or Reserves, in terms of enhancing wider public understanding and visibility of the armed forces, and the wider social value which might follow from the existence in civilian society of individuals with the skills and attitudes developed within the USUs.

A key conclusion from the interviews with graduates with USU experience is the idea of the range of components which contributed to the value of the units. The units are not reducible to one single thing, but have value to individuals and the armed forces in a range of different ways.

Looking beyond the empirical data to consider the context, we have a number of additional observations. The first concerns the availability of the opportunity to participate in a USU. As we discussed in Chapter 1, although restricted to a smaller academic elite in the past, a university education in the present is not an unusual experience for young people in the 18-24-year-old age group, and particularly not for those from middle and higher income backgrounds. Degreelevel education has become normalised, routine, expected and unexceptional. The USU experience stands out in contrast, and was perceived by graduates to have substantial individual benefit. As we have noted, the numbers participating in the units are small as a proportion of the overall UK student population, and smaller as a proportion than in the past, and thus the USU experience remains distinctive. A number of graduates discussed ideas around the expansion of the units, either in terms of the size of individual units or the total number of units, being of the view that the value of the experience could and should be available to a wider number of students. It was not within the remit of the research to adjudicate on questions about the expansion or contraction of the USUs; this is properly a matter for the Ministry of Defence and the three armed forces themselves, in the context of wider debates about defence structures and strategies. The point remains, however, that for graduates with unit experience, there was a strong sense that the experience should be more widely available.

The second point concerns the necessity of considering value-for-money, whilst recognising the non-financial benefits of the units within a context of public sector austerity where state expenditure is being slashed. The USUs represent a financial investment through the defence budget. The intention of the research was explicitly not to provide a cost-benefit analysis using economic methodologies to establish this, but rather to explore using a sociological approach as to whether or not the USUs have value, and if so, to whom. That said, the question of value-for-money was raised by a number of graduate 
interviewees. The financial contexts shaping USUs come not only from defence budgets, but from the current student funding system. As one interviewee noted, his generation got paid, and did not pay tuition fees, so 'we could really commit. He reckoned that the pay provided payback in recruitment and 'it's got to be cheaper than careers offices', 'people end up as advocates so it's worth paying for'.

A significant proportion of our interviewees were curious about the overall purpose of the research, and whether it had been initiated or would be used as the basis for cost-cutting measures. One interviewee put it most succinctly when he said:

'I see it in my day job, accountants can't see the benefit of investing time and energy in people, but hopefully, somebody somewhere, buried in one of the MOD offices or Land Command, the Army, actually says no, save the OTCs. Hopefully your research will show the benefits and show them that. For me it was life-changing. I just couldn't imagine it not being part of my life, and I'd be sorry to hear if that kind of opportunity was taken away from anyone else.' 